\title{
Update in the Treatment of Severe Sepsis and Septic Shock
}

\author{
D. Boodoosingh, C. Cruz, M. Egozcue, \\ R. Fernandez, V. Salinas and S. Valentin \\ Pulmonary Program Physicians \\ San Juan City Hospital \\ Puerto Rico
}

\section{Introduction}

The mortality rate of severe sepsis and septic shock has remain high and always has been recognized as one of the most common cause of death worldwide. On the other hand, new interventions has been shown to decrease the complications of this syndrome, even reducing the percent of deaths from over $50 \%$ to $30-40 \%$ in some studies.

In this chapter, we will discuss some of these therapies including the most important studies leading to better outcomes in the treatment of the above condition.

\section{Diagnosis}

So far there is no definitive test for the diagnosis of severe sepsis or septic shock. When the human body is exposed to an insult, whether caused by bacteria, trauma, burn, or drug overdose, the individual tends to respond differently depending on their health status and the presence or absence of co-morbidities. Despite no specific test available, there are certain findings that lead us to the diagnosis. These include tachycardia, tachypnea, leukocytosis or leucopenia, fever or hypothermia; all of them are basically criterias defining the Systemic Inflammatory Response Syndrome (SIRS). In addition, the presence of altered mental status, hyperbilirubinemia, metabolic acidosis or respiratory alkalosis and thrombocytopenia could also be useful.

Severe sepsis is known as an acute organ dysfunction secondary to infection. When evaluating a patient with this syndrome time becomes our worst enemy. The organism/s responsible for the acute illness should be identified within the first hours. Appropriate cultures should be obtained before antimicrobial therapy is initiated to confirm the presence of infection and proceed with de-escalation of antibiotic therapy after a susceptibility profile is available. Two quantitative blood cultures should be taken and in patients with indwelling catheters for more than 48 hours, at least one blood culture should be drawn through each lumen of the vascular access [1]. When the same organism is recovered from both cultures, the likelihood that the organism is causing the severe sepsis is enhanced. Quantitative cultures of other body sites, such as urine, cerebrospinal fluid, wounds and /or respiratory secretions should also be obtained if they are considered to be the source of infection. It is important to understand that obtaining cultures before the initiation of 
therapy should only be done if not associated with significant delay in antibiotic administration.

Imaging studies might also be necessary to identify the source of infection, especially when the presence of foreign body or drainage is suspected to be the cause of severe sepsis. However, some patients may be too unstable to undergo invasive procedures or be transported outside the intensive care unit. In such cases bedside ultrasound can be useful.

The potential role of biomarkers in the diagnosis of severe sepsis remains unclear. The use of pro-calcitonin level has demonstrated controversial results since it can be altered in patients with an acute inflammatory process other than infection [2]. In the near future, it is expected that rapid diagnostic methods, such as polymerase chain reaction, be available for quicker identification of pathogens and antimicrobial resistance patterns [3].

\section{Source control}

Source control is known as the rapid diagnosis of the specific body site of infection amenable to proceed with control measures such as abscess drainage, debridement of infected necrotic tissue and removal of a potentially infected device. Possible infectious foci include: intra-abdominal abscess, intestinal infarction and/or gastrointestinal perforation, cholangitis, pyelonephritis, empyema and septic arthritis. Identification of these sites of infection should be within the first six hours of presentation $[4,5]$.

When source control is required minimally invasive interventions should be employed. For example, performing percutaneous drainage rather than surgical intervention of an abscess [6]. If less invasive approaches are inadequate or there is uncertainty about the diagnosis, then more aggressive measures should be considered. When making such decisions the benefits versus risks as well as the patient's preferences and clinician's expertise must be considered [7].

When an intravascular access device has been identified as the possible cause of severe sepsis removal of the device should be done after other vascular access has been established $[8,9]$. Special attention should be given when the suspected source of infection is a peripancreatic necrosis. Definitive intervention should be delayed until adequate demarcation of viable and non-viable tissue has been made. In this case endoscopic rather than surgical drainage of biliary tree should be considered taking into consideration what represents the least physiologic insult for the patient [10].

\section{Antibiotic therapy}

Administration of antibiotics is considered as important as establishing a vascular access and giving fluid resuscitation. Therapy should be started within the first hour of recognition of septic shock. In some cases this may require additional vascular access, however this shouldn't represent a delay in the infusion of antibiotics since this has been associated with increased mortality [11, 12]. The choice of empirical antibiotics will depend on patient's history, including drug intolerance, co-morbidities, the clinical syndrome and susceptibility patterns of pathogens in the hospital, community and those that have previously infected the individual. Recently used antibiotics should definitely be avoided.

Another consideration is whether fungal infection with Candida species is the cause of sepsis. Risk factors for candidemia include: central venous catheters, total parenteral nutrition, broad- spectrum antibiotics, high APACHE scores ( Acute Physiology and 
Chronic Health Evaluation II), acute renal failure, prior surgery ( particularly abdominal surgery), gastrointestinal perforations and anastomotic leaks [13, 14, 15 ]. Immunocompromised patients such as those with hematologic malignancies, recipients of solid organ or hematopoietic stem cell transplants and those receiving chemotherapy are also at increased risk of candidemia [16].

All patients with septic shock should be treated initially with broad-spectrum antibiotics to cover the most common or likely pathogens. It has been demonstrated that failure to initiate appropriate therapy against the pathogen that is later identified as the cause of infection is associated with increased morbidity and mortality $[17,18]$. Therapy should be re-evaluated on a daily basis for four reasons: to optimize activity, to prevent the development of resistance, and, to reduce toxicity and costs.

Combination therapy should be given to those patients with risk factors for Pseudomonas infection and neutropenia, defined as an absolute neutrophil count (ANC) less than 1500. Although clinical evidence has failed to demonstrate that combination therapy produces superior clinical outcome for individual pathogens in a particular patient group, combination therapies do produce in vitro synergy against pathogens in some models [19, 20, 21, 22]. The rationale in administering combination therapy for suspected Pseudomonas infection is to increase the likelihood that at least one drug will be effective against that strain. This intervention has demonstrated to have a positive effect on outcome [23].

Duration of therapy should not exceed more than three to five days and de-escalation to single therapy should be performed as soon as susceptibility profiles are available. Narrowing the spectrum of antibiotic coverage and reducing the duration of therapy will decrease the possibility that the patient develops superinfections with pathogens or resistant organisms such as Candida species, Clostridium dificile, or vancomycin-resistant Enterococcus faecium. Therapy should be prolonged from seven to ten days in patients with slow clinical response and those who are immunocompromised or have a source of infection that cannot be controlled. If the cause of the clinical syndrome has been confirmed to be of noninfectious etiology, antibiotic therapy should discontinue immediately. This will decrease the likelihood that the patient becomes infected with drug resistant pathogens.

\section{Hemodynamic management in severe sepsis and septic shock}

Early sepsis signs are very difficult to diagnose,usually with nonspecific presentations. Patient who arrives with an unapparent infection can progress to a lethal form of disease.

In 1992 The Society of Critical Care Medicine Conference consensus defined sepsis as a systemic inflammatory response that includes 2 or more clinical findings: temperature, respiratory rate, heart rate and white blood cell count in the setting of presumed or a documented infection [24].

Severe sepsis is hallmarked by concomitant organ hypoperfusion or dysfunction $[25,26,27]$. Sepsis induced hypotension is defined as a systolic blood pressure $(\mathrm{SBP})<90 \mathrm{mmh}$ or mean arterial pressure $<65 \mathrm{mmh}$ or SBP decease $>40 \mathrm{mmh}$ or 2SD below normal for age in absence of other cause of hypotension. Septic shock is defined as sepsis induced hypotension persisting despite adequate fluid resuscitation basically requiring vasoactive drugs.

Early recognition of sepsis with integrated approach screening, triggering evidence-based protocolized care, is anticipated to reduce sepsis morbidity and mortality [28]. The Surviving Sepsis Campaign (SSC) provided some of the best clinical evidence for the management of severe sepsis and septic shock. 


\section{Initial resuscitation}

Patients with septic shock often require early and vigorous resuscitation with an integrated approach directed to rapid restoring systemic oxygen delivery and improving tissue oxygenation.

The first priority involves stabilization of the airway and breathing,with supplemental oxygen and if necessary institution of mechanical ventilation.

Second assessment of perfusion should be done (hypotension persisting after initial fluid challenge, blood lactate $\geq 4 \mathrm{mmmol} / \mathrm{L}$ ). Once hypoperfusion is recognized, early restoration of perfusion is necessary to limit secondary organ dysfunction and reduce mortality. During the first 6 hours of resuscitation, the goals should include: Central venous pressure $8-12 \mathrm{~mm}$ $\mathrm{Hg}$ with a Mean Arterial Pressure (MAP) over $65 \mathrm{mmHg}$, a urine output $\geq 0.5 \mathrm{ml} / \mathrm{kg} / \mathrm{hr}$ and finally a Central venous (superior vena cava) or mixed venous oxygen saturation $\geq 70 \%$ or $\geq 65 \%$ respectively. If Svo2 is less than $70 \%$, packed of red blood cells (PRBC) are transfuse to achieve an hematocrit level of $30 \%$. If central venous pressure, MAP and hematocrit were optimized and Svo2/ScVo2 remained below $70 \%$ dobutamine is recommended to increase cardiac output and oxygen delivery.

The early goal directed therapy has been shown to improved survival for emergency department (ED) patients with severe sepsis and septic shock. This evidence comes from a randomized controlled single center trial that assigned 253 patients with severe sepsis or septic shock to receive protocolized early goal directed therapy during the first 6 hours in ED or to receive standard therapy before admission in ICU. These resuscitation goals reduced the in hospital mortality from $46.5 \%$ to $30.5 \%(P=.009)$, a 28 days mortality rate $(p=0.1)$ and at 60 day $(p=0.3)$ [28].

In 2004 the international group experts published first internationally accepted guidelines [29].Eventually from 2006 to 2007 the group met again to update the guidelines using new evidence [30]. Central venous pressure is currently commonly used as guide for resuscitation, although there are recognized limitations to ventricular filling pressures estimated as surrogate for fluid resuscitations [31, 32]. In mechanical ventilated patient target CVP of 12 to $15 \mathrm{mmHg}$ is recommended to account for impediment of filling due to increase intrathoracic pressure [33]. Other cases to consider higher CVP include increased abdominal pressure and diastolic dysfunction [34].

The MAP is the most powerful predictor of mortality, commonly used as an indicator of perfusion pressure [35]. Current recommended levels are between $60-65 \mathrm{mmHg}$ in view of adequate autoregulation of blood flow to vital organs [36].

Oxygen is delivered to the tissues as a product of cardiac output (heart rate $x$ stroke volume) and oxygen content (hemoglobin oxygen saturation $x$ hemoglobin $x 1.34)+($ partial pressure of oxygen $x .003$ ). The tissues extract a percentage of the delivered for cellular respiration and the remaining returns to venous circulations. This amount can be measure from pulmonary artery (SvO2, mixed venous oxygen saturation) or by central venous circulation (central oxygen saturation). $\mathrm{ScvO} 2$ is only measure with a pulmonary catheter. However, the $\mathrm{ScvO} 2$ can be obtained by central insertion of the superior vena cava or right atrium. Pulmonary artery catheter for hemodynamic monitoring and mixed venous saturation has not shown any difference in outcome $[37,38]$ but it is used in selected cases.

The measurement of Scvo2 is 5-6\% higher than Sv02, but some studies has shown excellent correlation $[39,40]$. So basically a targeted $\mathrm{SvO} 2$ has demonstrated better outcome in this population. 


\section{Fluid therapy}

Septic shock is associated with substantial volume depletion and myocardial dysfunction. The ventricular filling pressure is usually low due to an increase in external loses from gastrointestinal or urinary tracts, bleeding, skin surface or internal loses due to exudation or transudation of bloody fluids. This leads to a generalized vasodilatation and peripheral blood pooling, consequently decreasing the intravascular volume. Adequate fluid resuscitation therefore is one of the cornerstones of the management of septic shock. The aim is the restoration of intravascular fluid volume, reestablish effective tissue perfusion, increase cardiac output and systemic oxygen delivery.

The outcomes advantages between crystalloid and colloids solutions continue to remain unsolved. The recent sepsis campaign guidelines cannot recommend one type or another. The Saline versus Albumin Fluid Evaluation (SAFE), a multicenter randomized trial study showed no difference in 28 day all mortality cause, organ dysfunction, duration of mechanical ventilation, day of renal replacement, hospital or ICU length of stay [41].

However, other study compared $10 \%$ pentastarch (a low molecular weight hydroxyethyl starch) with ringer's lactate and the first therapy was associated with higher rates of renal replacement therapy [42].

As the volume of distribution is much large for crystalloids than for colloids, the use of crystalloids for resuscitation requires more fluid and infusion periods to achieve comparable hemodynamic endpoints. Though less colloid is requires, volume expansion with colloid is more expensive.The fluid challenge in patient with suspected hypovolemia may be give at rate of $500-1000 \mathrm{ml}$ of crystalloids or $300-500 \mathrm{ml}$ of colloids over $30 \mathrm{~min}$ and repeated on response (blood pressure, heart rate, urine output) and tolerance (evidence of intravascular fluid overload).

Since the validation of CVP measurements in patients with sepsis is widely debated, other methods has emerged to assess fluids responsiveness. Echocardiography can be use to estimate Left ventricular End Diastolic volume but it is skill operator dependant [43]. Pulse Pressure Variation (PPV) during pressure breath can be used to predict responsiveness cardiac output to change preload [44]. PPV in mechanical ventilated patient is useful for assessing preload responsiveness [45].

Other controversial topics are the fact that excessive amount of fluid may be harmful to the patients with septic shock. Multiple studies have correlated positive fluid balance with reduces survival in ARDS [46] and sepsis [47]. Other study of 87 patients in mechanical ventilation showed that positive fluid balance were associated with failure of spontaneous breathing trials [48].

A prospective study, The Fluid and Catheter Treatment Trial (FACTT) randomized 1,001 patients with acute lung injury or ARDS to conservative (CVP $<4 \mathrm{~mm} \mathrm{Hg}$ or pulmonary artery occlusion pressure [PAOP], $<8 \mathrm{~mm} \mathrm{Hg}$ ) vs. liberal (CVP, 10 to $14 \mathrm{mmHg}$, or PAOP, 14 to $18 \mathrm{~mm} \mathrm{Hg}$ ) fluid management and concluded that there was no mortality difference at 60 days, but the conservative fluid strategies improved lung function, ventilator free days and reduce ICU length of stay [49].

A new retrospective study review from the Vasopressin in Septic shock trial (VASST) in which was analyzed the positive fluid balance and determined correlation with CVP at $12 \mathrm{hrs}$ and during subsequent days. The study found increase mortality with positive fluid balance early in resuscitation and cumulative for 4 days. The CVP may be use as a gauge to fluid balance $<12 \mathrm{hrs}$, but becomes an unreliable marker of fluid balance thereafter. The overall data suggest 
the optimal survival occurred at CVP of $8 \mathrm{mmHg}$ and positive fluid balance of 31 during first $12 \mathrm{hr}$; however a randomized control studies is necessary to prove this [50].

The approach of fluid resuscitation in sepsis shock patients suggest that should be liberal in the first $6 \mathrm{~h}$ of acute resuscitation, guided by Svo 2 or Scvo2. Once the patient is adequately resuscitated, fluids should be hold without the necessity of maintenance therapy. The intravascular status should be continuing monitoring with physical examination with observation of sign of hypoperfusion, weight, input and output chart and other measures [51].

\section{Vasoactive therapy}

When the fluid administration fails to restore an adequate arterial pressure and organ perfusion, a vasoactive agent should be started. The ultimate goals are to restore effective tissue perfusion and normalize cellular metabolism.

In shock state, the estimation of blood pressure using a cuff may be inaccurate and the use of arterial catheterization provides more precise and reproducible measurements of arterial pressure [52].

Most experts recommend a MAP $\geq 65 \mathrm{~mm} \mathrm{Hg}$.

\section{Norepinephrine}

Norepinephrine is the endogenous mediator of the sympathetic system having a strong aadrenergic activity with less $\beta$-adrenergic effects.It increases MAP by vasoconstriction, with small $(10-15 \%)$ increase in cardiac output and stroke volume [53-58] .Filling pressure is either unchanged[59] or modestly increased (1-3 $\mathrm{mm} \mathrm{Hg})$ [54-57].

In open labels trials, norepinephrine at doses ranges 0.01 to $3.3 \mu \mathrm{g} / \mathrm{kg} / \mathrm{min}$ has demonstrated to increase MAP in patients who remained hypotensive after fluid resuscitation and dopamine [54-56, 58, 60, 64-65].

A randomized trial compared vasopressor agents in 32 resuscitated septic patients in which either dopamine or norepinephrine were given to keep homodynamic derangements. Dopamine was successful only in 31\% vs. 93\% treated with norepinephrine [63].

Another larger multicenter randomized trial study, which compared dopamine vs. norepinephrine for treatment for any kind of shock (cardiogenic, hypovolemic, septic), found no significant death rate at 28 days.However, there were more arrhythmic events among patients treated with dopamine.Also, patients who suffered cardiogenic shock and were managed with dopamine had an increase mortality rate at 28 days. This and other studies suggested that norepinephrine is a safer drug in cardiogenic shock and myocardial infarction patients due to tachyphylaxis [67].

Other important multivariate analysis included 97 septic shock patients and was statistically significant for a reduced mortality by the use of the norepinephrine. The use of high use dopamine, epinephrinephrine or dobutamine had no significant effect [68].

The studies of norepinephrine with splanchnic blood flow in septic patient have mixed results. A recent one compared norepinephrine, dopamine and epinephrine for septic shock and there was no significant difference between them [69].

\section{Dopamine}

Dopamine has predominantly $\beta$-adrenergic effects in low to moderate dose ranges (up to 10 $\mu \mathrm{g} / \mathrm{kg}$ per minute). Higher doses cause a-adrenergic predominance leading to arterial vasoconstriction and increase blood pressure. 
It may be useful in patients with decrease systolic dysfunction but causes more arrhythmias than norepinephrine [70]. Although is has shown diuretic properties,it is not recommended for above purposes [71] probably due to its neuroendocrine effects, which may interfere with prolactin, thyroid, pituitary function and some of the immunosuppressive functions [72-73].

Moreover, the use of Dopamine at "renal dose" has been discouraged due to ample evidence in meta-analysis and high quality prospective trial .An important one included 328 criticall ill patients with early renal dysfunction and were separated in groups for low dose dopamine or placebo. No difference was found in the primary outcome (peak serum creatinine level, need for renal replacement and urine output). Other variables such as survival or hospital length of stay were unremarkable as well.

Multiple recent studies has shown more detrimental effects with Dopamine.For example, the use of dopamine was associated with an increased mortality in patients with shock in a prospective multicenter observational study of 198 Europeans ICU [74].

In conclusion, many experts have recognized that Dopamine should not be the first vasoactive drug in patients in shock and some of them recommended that should not be used anymore in patients with septic shock.

\section{Epinephrine}

Epinephrine has potent $\beta 1-\beta 2$ and a1-adrenegic activity, although the elevated MAP in sepsis comes mainly form an increase in cardiac output [75].The major concerns in use of epinephrine are: higher myocardial oxygen demand, hyperglycemia,increased lactate levels and a reduction in regional blood flow[76-79].

Myburhg and colleagues performed a prospective multicenter, double blinded and randomized control trial in 280 ICU patients comparing epinephrine to norepinephrine founding no difference in the time to achieve arterial pressure goals, 28 day mortality, 90 day mortality.However, $13 \%$ of the patients in the epinephrine group were withdrawn from the study because lactic acidosis or tachycardia[84].

Another randomized control trial conducted by Annane and colleagues compared 330 patients with septic shock and evaluated the efficacy of norepinephrine with or without dobutamine against epinephrine alone [85]. They found that there was no difference in efficacy or safety between the two groups. For instance,epinephrine is not currently recommended as fist line vasopressor therapy in view of concerns about tachyarrhythmias and his effects on gastric perfusion.

\section{Phenylephrine}

Phenylephrine works at the a1 receptors causing increased blood pressure by vasoconstriction. Its use in septic shock has had controversial results but so far there has been only few related studies.

In comparison with norepinephrine, phenylephrine reduces splanchnic blood flow, oxygen delivery and lactate uptake [86].On the other hand,it may be a good option when tachyarrhythmias limit therapy with other vasopressors.

\section{Vasopressin}

Arginine-vasopressin is an endogenous hormone that is release in response to decrease intravascular volume and increase plasma osmolality. Vasopressin constrict vascular 
smooth muscle though V1 receptors. It also increases the responsiveness of the vascular bed to catecholamines $[87,88]$. Vasopressin may also increase blood pressure by inhibiting vascular smooth muscle nitric oxide [89] production and K +-ATP channels [90].

A newer interest has emerged as an additive vasoconstrictor in patients with septic shock resistant to catecholamines [90]. Vasopressin have been found to be in lower levels than expected in patients with septic shock, suggesting relative deficiency. Its combination with norepinephrine increases the splanchnic flow and urinary output [91]. Several smallrandomized studies comparing vasopressin with norepinephrine have demonstrated that initiation of it decreases catecholamine requirements [92].

A large, multicenter, randomized trial (VASST) [97] with 778 patients was done to determine whether norepinephrine and vasopressin decreases mortality compared with norepinephrine alone. No difference was found in mortality, ICU or hospital length of stay, discontinuation of vasopressors or organ dysfunction. The use of norepinephrine infusion was significantly lower in cases with vasopressin dose of $0.03 \mathrm{U} / \mathrm{min}$, but vasopressin seems to be better in less severe group. New retrospective analysis of the VASST suggests a beneficial effect between vasopressin and corticosteroid in patients with septic shock that were also treated with steroids. Patients with vasopressin with corticosteroids have significantly increased in plasma vasopressin levels. Vasopressin at $0.03 \mathrm{u} / \mathrm{min}$ added to norepinephrine seems to be as safe as effective as norepinephrine in fluid resuscitated patients with septic shock.

\section{Dobutamine}

Is an inotrope that has variable effects on blood pressure due to $\beta 1$ and $\beta 2$ adrenergic agonist effect resulting in an increase heart rate and cardiac contractility. Dobutamine should be considered in patients who have low cardiac output in the presence of adequate ventricular filling pressures and appropriate mean arterial pressure [28-29] .

In septic patients, it increases oxygen delivery and consumption. As part the early goal directed therapy dobutamine was associated with significant absolute reduction in mortality [28].

An inotrope should be considered to maintain an adequate cardiac index, mean arterial pressure, mixed venous oxygen content and urine output . Other available agents includes phosphodisterase inhibitors such as milrinone and enoximone, and calcium sensitizers such as levosimedan. There are currently inadequate data to recommend them in septic shock.

\section{Severe sepsis/septic shock and the use of steroids}

Sepsis syndrome is characterized by having a disequilibrium between pro- inflammatory and anti-inflammatory cytokines leading to overproduction of IL-1, IL-6 and TNF-a from the lymphocytes, macrophages and endothelial cells [100] . It is known that TNF- alfa and IL-6 decreases cortisol levels from the adrenal gland and ACTH production from the pituitary gland resulting in secondary adrenal insufficiency in approximately 16.3 to $55 \%$ of patients [101] . Systemic steroids might then have a beneficial role by inhibiting proinflammatory cytokines, nitric oxide and phospholipase A2 [102]. They also enhance the activity of adrenergic receptors and increased myocardial contractility resulting in improvement of hemodynamics response.

Hydrocortisone is usually the steroid of choice because it is the synthetic derivative of cortisol and also has intrinsic mineralocorticoid activity. After the study by Schumer, a short 
course of high- dose corticosteroids became an accepted therapy [103] . Subsequent studies, however, did not confirm a survival benefit with this regimen and suggested an increase in superinfection-related mortality were patients went from being immunomodulated to being immunosupressed.

Multiple randomized trials in patients with septic shock confirm that low-dose steroid therapy in these patients improves blood pressure, thereby, causing reduction in vasopressor support.

In 2002 Annane demonstrated a reduced mortality $(p=0.04)$ in a subgroup of patients that were non responders to an adrenocorticotropic hormone tests (ACTH test) but the mortality rate was increased $(p=0.96)$ in patients without evidence of relative adrenal insufficiency (responders) [104] . In 2008 Russell found out a reduced mortality in a subgroup of patients with severe septic shock in those receiving steroids and vasopressin versus norepinephrine and steroids raising the concern that vasopressin may increase the levels the intrinsic cortisol levels [105].

Bauer found a positive interaction of vasopressin and corticosteroids in a nonrandomized cohort study of patients with septic shock, all of whom received vasopressin. Patients who received corticosteroids and vasopressin had lower mortality rates (47.6\% vs. $80.9 \%$; $\mathrm{p}=0.02)$ compared with patients who did not receive corticosteroids with vasopressin. Furthermore, a randomized, blinded, placebo-controlled trial $(n=100)$ of vasopressin plus corticosteroids or placebo in human cardiac arrest found a beneficial interaction of vasopressin and corticosteroids. Patients who received vasopressin plus corticosteroids had more frequent return of spontaneous circulation $(81 \%$ vs. $52 \% ; \mathrm{p}=.003)$ and higher survival rates $(19 \%$ vs. $4 \%, p=.02)$ than patients who received vasopressin plus placebo.

Finally a multicenter, randomized, double-blind, placebo-controlled study called Corticosteroid Therapy of Septic Shock (CORTICUS) study, evaluated the efficacy and safety of low-dose hydrocortisone therapy in a broad population of patients with septic shock[106]. The use of low-dose hydrocortisone had no significant effect on the rate of death in 251patients with septic shock versus placebo at 28 days, regardless of the patients' adrenal responsiveness to corticotropin. The proportion of patients in whom reversal of shock was achieved was similar in the two groups, though this goal was achieved earlier in patients who received hydrocortisone. On the basis of these findings, hydrocortisone cannot be recommended as general adjuvant therapy for septic shock (vasopressor responsive), nor can corticotropin testing be recommended to determine which patients should receive hydrocortisone therapy. Hydrocortisone may have a role among patients who are treated early after the onset of septic shock who remain hypotensive despite the administration of high-dose vasopressors and adequate fluid resuscitation.

\section{Activated protein $C$ and its role in severe sepsis/septic shock}

Sepsis is associated with alterations in the blood coagulation, fibrinolytic systems and inflammatory pathway. This leads to disorders of tissue perfusion that generate multiple organ system failure with depletion of platelets and coagulation factors along with the activation of natural inhibitors of coagulation. Activated protein C (APC), an endogenous protein that promotes fibrinolysis and inhibits thrombosis and inflammation, is an important modulator of the coagulation and inflammation associated with severe sepsis[107] . It is converted from its inactive precursor, protein C, by thrombin coupled to thrombomodulin. The conversion of protein $C$ to activated protein $C$ may be impaired 
during sepsis as a result of the down-regulation of thrombomodulin by inflammatory cytokines. Reduced levels of protein $\mathrm{C}$ are found in the majority of patients with sepsis and are associated with an increased risk of death.

A randomized, double-blind, placebo-controlled, multicenter trial was conducted with recombinant human activated protein $C$ in 1998 in 1690 patients to evaluate mortality at 28 days [108]. The PROWESS (Protein C worldwide evaluation in severe sepsis) trial was completed in 2001 and statistical analysis indicated a decreased 28th mortality rate of $30.8 \%$ in the placebo group compared with $24.7 \%$ in the drotrecogin alfa group. The difference in the mortality was limited to patients with a higher risk of death, that is, APACHE II scores $>25$. In these groups mortality was reduced from $44 \%$ in the placebo group to $31 \%$ in the treatment group. Efficacy was doubtful in patients with low risk for death and serious bleeding was higher in the APC group.

In 2005 the ADRESS trial evaluated the efficacy of APC in patients with APACHE score $<25$ or single organ failure and there was no difference in mortality among both groups at 28 days [109].

There is increased risk for serious bleeding and no beneficial effect in those patients with low risk for death, such as those with single organ failure or an APACHE II score less than 25 [110].

More recently a Cochrane database submitted their review on APC and again no difference in mortality was observed in approximately 4434 adults with sepsis. Increased risk for serious bleeding was noted and for this reason a new trial was requested by the FDA that should be completed at the end of 2011.

On the basis of this findings APC is recommended for patients with severe sepsis and high risk for death if there is no contraindications.

\section{Glucose control in ICU}

Blood glucose control was originally investigated in the setting of diabetes because uncontrolled levels seemed to predisposed to multiple infections (e.g., cellulitis, postoperative wound infections). Although the exact pathogenesis was unknown, it was speculated that the increased risk of infection was related to decreased cellular immune function [111]. Later studies (both in animals and humans) demonstrated that the depressed ability to fight off infection was a result of impaired polymorphonuclear leukocyte function, chemotaxis, and phagocytosis.

Extensive observational data have shown a consistent, almost linear relationship between blood glucose levels in hospitalized patients and adverse clinical outcomes, even in patients without established diabetes [112].

Van den Berghe reported a dramatic $42 \%$ relative reduction in mortality in the surgical ICU when blood glucose was normalized to 80 to $110 \mathrm{mg}$ per deciliter (4.4 to $6.1 \mathrm{mmol}$ per liter) by means of insulin infusion in a prospective, randomized fashion [113]. Five years later, the same investigators reported findings from their medical ICU, revealing no mortality benefit from intensive glucose control, except in a subgroup requiring critical care for 3 or more days [114].

A parallel-group, randomized, controlled trial involving adult medical and surgical patients admitted to the ICUs of 42 hospitals was conducted from December 2004 through November 2008 to evaluate mortality in patients assigned to tight glucose control versus conventional glucose control (NICE SUGAR Trial)[115] . Ninety days after randomization, 
829 of 3010 patients $(27.5 \%)$ in the intensive-control group had died, as compared with 751 of 3012 patients $(24.9 \%)$ in the conventional-control group. Severe hypoglycemia was significantly more common with intensive glucose control. In the basis of this findings, glucose control with intravenous insulin should be started in patients with severe sepsis upon stabilization at ICU when glucose levels are above 180 (1B) with a goal blood glucose target in the range of $150 \mathrm{mg} / \mathrm{dL}$ (2C). The American Association of Clinical Endocrinologists recommends a glucose range of 140 to $180 \mathrm{mg} / \mathrm{dL}$ for most hospitalized persons.

\section{Mechanical ventilation in sepsis}

The strategies to ventilate patients with severe sepsis have been changing for the last decades. Multiple studies demonstrated that ventilating with the usual tidal volume may have detrimental effects causing what is now recognized as ventilator induced lung injury. This complication have led to new forms of ventilation called lung protective management in which lower volumes are provided in order to prevent alveolar overdistention.

Sepsis itself can induce acute lung injury (ALI) in about $50 \%$ of the cases. ALI is defined as an acute onset insult resulting in bilateral radiographic infiltrates, pulmonary artery wedge pressure $\leq 18 \mathrm{~mm} \mathrm{Hg}$ when measured by a pulmonary catheter, an echocardiogram showing no evidence of left atrial hypertension, and an arterial oxygen tension to fraction of inspired oxygen ratio $(\mathrm{PaO} 2 / \mathrm{FiO} 2)$ of 201 to $300 \mathrm{mmHg}$. The difference between ARDS is mainly the worsening of hypoxemia having above ratio less than $200 \mathrm{mmHg}$ [116].

With conventional ventilation,patients with ARDS had higher mortality rate when used prior the new recommendations. Lung protective ventilation has shown a decrease mortality rate and ventilator-induce lung injury [117]. This intervention also know as low tidal volume ventilation involved an initial tidal volume of $6 \mathrm{ml} /$ kilogram of predicted body weight (PBW) aiming for a plateau pressure of $\leq 30 \mathrm{~cm} \mathrm{H2O}$. If plateau pressure remains $>$ 30 after reduction of tidal volume, it should be reduced further to as low as $4 \mathrm{ml} / \mathrm{kg}$ PBW [118]. In contrast to the conventional ventilation that involved a tidal volume of 12 $\mathrm{ml} /$ kilogram of body weight with low positive end-expiratory pressure (PEEP), protective ventilation avoids alveolar overdistention and end-expiratory collapse [119]. The titration of the PEEP should approach a balance between lung recruitment and overdistention, barotrauma, and hypotension in order to maintain adequate oxygenation (arterial oxygen saturation over $88 \%$ ). This permit lower $\mathrm{FIO}_{2}$, decreasing the risk of oxygen toxicity. High PEEP level may increase airway pressures and lung volumes, which could contribute to ventilator induced lung injury from overdistention [120]. The optimal strategy to set PEEP has not been established [118,120,121].

The low tidal volume ventilation can result in respiratory acidosis which now is known as permissive hypercapnia. The respiratory rate is usually increased to keep adequate minute ventilation. The increase on carbon dioxide can cause vasodilation, increase in heart rate, cardiac output, blood pressure, pulmonary vascular resistance and decrease renal blood flow; but modest hypercapnia has been demonstrated to be safe in clinical trials. This ventilation is allowed in order to prevent pulmonary overdistention and consequently negative effect in ALI/ARDS [122].If severe respiratory acidosis, $\mathrm{pH}<7.15$, develops the infusion of sodium bicarbonate may be considered. These type of ventilation is contraindicated in patients with cerebral disorders such as cerebrovascular insults, trauma, or space-occupying intracranial lesions because it may increase the intracranial pressure. 
In patients with refractory hypoxemia, prone position ventilation has been recommended despite no benefits in survival. Proper precautions should be taken to avoid complications like pressure sores, accidental dislodgment of the endotracheal tube and central venous catheters [118]. Same results has been noticed in studies with high frequency oscillatory ventilation and Extra Corporeal Membrane Oxygenation (ECMO).

Noninvasive ventilation (NIV) has been suggested in patients with ALI/ARDS since it allows better communication, reduces incidence of infection, requirements for sedation and duration of intensive care unit stay [124]. Its use should be considered only in hemodynamically stable patients who are cooperative, able to protect the airway and spontaneously clear the airway of secretions; and who are anticipated to recover rapidly from the precipitating insult [124]. Continuous positive airway pressure (CPAP) and noninvasive positive pressure ventilation (NIPPV) are the most commonly used modes. In NIPPV, two different pressures are used: inspiratory positive airway pressure (IPAP) and expiratory positive airway pressure (EPAP), whereas CPAP maintains a constant positive airway pressure throughout the respiratory cycle. NIPPV may confer an advantage over CPAP by reducing the work of breathing during inspiration by providing additional inspiratory pressure. The main goal of NIV in patients with ALI/ARDS includes improvement of hypoxemia, to unload the respiratory muscles and eventually relieve dyspnea. A practical approach has been postulated, it should be use judiciously in selected patients to prevent decrease in survival if intubation is delayed [124].

The discontinuation of mechanical ventilation crucial and should be base on weaning protocol to assess readiness of successful extubation, reducing the duration and the complications related to it [118].

\section{Sedation, analgesia, and neuromuscular blocked in sepsis}

Patients critically ill with sepsis usually require control of anxiety, agitation and pain, especially when they are with mechanical ventilation support.There are several options of sedative-analgesic medications including benzodiazepines,opioids and neuroleptics. The intention is to achieve adequate comfort and safety using protocols with a sedation goal [125]. This accomplishment should be use according to the patient clinical condition. Several scoring scale has been validated, none superior to the other; Riker Sedation-Agitation Scale (SAS), Motor Activity Assessment Scale (MAAS), Minnesota Sedation Assessment Tool (MSAT), and Richmond Agitation-Sedation Scale (RASS) and Ramsay Sedation Scale [126].

The use of protocol-directed sedation can reduce the duration of mechanical ventilation, the intensive care unit and hospital lengths of stay, and the need for tracheostomy [127]. The use of the combination of spontaneous awakening trials (SATs), daily interruption of sedatives, with spontaneous breathing trials (SBTs) for the management of mechanically ventilated patients in intensive care results in better outcomes. It can also decrease mechanical ventilation, intensive care and hospital stay with survival improvement [128].

The pain management should be assessed frequently using a pain scale appropriate to patient's condition. The numeric rating scale has been recommended in critical ill patients because it is easier to apply [126]. Patients who cannot communicate behavioral pain scale (BPS) may be used. The pain intensity is evaluated by facial expression, movement of the upper extremities and compliance with ventilation [129].

The neuromuscular blocking agents (NMBAs) are not recommended, when possible, in septic patients due to prolonged neuromuscular blocked following discontinuation [125]. 
They should be use when appropriate sedation and analgesia cannot be achieved. The indications are to facilitate mechanical ventilation, improving chest wall compliance, preventing respiratory dys-synchrony, reducing peak airway pressures and decrease oxygen consumption by reducing work of breathing $(1,6)$. Patients receiving NMBAs should be assessed both clinically and by train-of-four monitoring, a peripheral nerve stimulation test, with a goal of adjusting the degree of neuromuscular blockade to achieve one or two twitches from a scale of 0 to 4 . This may reduce clinical recovery delay from NMBAs $[125,130]$. The administration of NMBAs in early ARDS was demonstrated to improve outcomes, it can decrease duration of mechanical ventilation, hospital stay and ventilation induce lung injury. Further studies are requiring before this clinical practice can be adopted [131].

The 'ABCDE' bundle has been proposed combining evidence-based interventions. It consist of A wakening and Breathing trial coordination, Choice of sedatives and analgesics, Daily delirium monitoring, Early mobility and exercise to improve the management of mechanically ventilated patients[132].

\section{Acute kidney injury and sepsis}

Acute kidney injury (AKI) is a common complication of sepsis and septic shock. Approximately 35 to $50 \%$ of the cases in the ICU can be attributed to sepsis [133 ] Patients with sepsis related AKI have higher hospital mortality, $74 \%$,compared with a $45 \%$ due to other diagnosis [ 134 ]. If renal replacement therapy is required the mortality rate rises further to as high as $80 \%$ [ 135 ].

The diagnosis of acute kidney injury, previously termed acute renal failure, is based on an elevation in the serum creatinine ( $\mathrm{SCr}$ ) levels. Many definitions have been proposed throughout the years since there was no real consensus on the degree of elevation required for the diagnosis of AKI. Because of this variability there was the need to develop a classification system that could propose a uniform definition within the medical community.

The Acute Dialysis Quality Initiative's "RIFLE" (Risk, Injury, Failure, Loss, ESRD) criteria was first established and included five categories, the first three of which define AKI and its severity largely by percentage increases in SCr over baseline [136]. The Acute Kidney Injury Network (AKIN) criteria was then proposed and [ 137 ] includes three stages, the last two of which are identical to the RIFLE criteria. Both definitions also incorporate severity and duration of oliguria as alternative criteria.

An improvement in urine output is a sensitive indicator of AKI, with an oliguric AKI associated to a poorer prognosis. Documentation of urine volume should be of general practice in the management of any acutely ill patient, especially those with sepsis or septic shock.

\section{Renal replacement therapy}

The decision to start renal replacement therapy (RRT) in patients with AKI should be based on the clinical aspects after careful evaluation of fluid, electrolyte and metabolic status of each individual patient.

Currently there are no evidence-based guidelines to suggest an optimal time to initiate treatment; it continues to be a clinical decision after the diagnosis of AKI is confirmed and before overt complications develop. 


\section{Continuous Renal Replacement Therapy (CRRT) vs. Intermittent Hemodyalisis (IHD)}

Intermittent hemodialysis-associated hypotension is estimated to occur in approximately $20-30 \%$ of treatments. Some of the causes are dialysis specific, such as excessive or rapid volume removal, changes in plasma osmolality, autonomic dysfunction, and anaphylactic membrane reactions [ 138 ]. CRRT is most frequently used in patients who are hemodynamically unstable, usually because of sepsis or severe cardiac dysfunction because it closely resembles normal physiologic renal function with slow correction of metabolic derangements and slow fluid removal. Despite this there is no clear evidence to support the superiority of either technique, regarding mortality in the ICU. Clinicians should choose a technique according to individual patient characteristics, nursing proficiency, and technical resources.

\section{Sodium bicarbonate replacement in sepsis}

Infusions of sodium bicarbonate long have been advocated to correct persistent metabolic acidosis. It was said to result in increased $\mathrm{pH}$ with less cellular dysfunction, improved cardiac contractility and the activity of vasopressor agents. However clinical studies suggest that this therapy should be tried as a last resort to improve the patient's clinical status.

In a recent review [ 139 ] the data supporting sodium bicarbonate infusion were evaluated. It seems clear from animal data that artificially increasing the $\mathrm{pH}$ does not improve such parameters as cardiac function or weaning of vassopressor agents. Further decrease in serum $\mathrm{pH}$ levels is possible since sodium bicarbonate is converted to carbon dioxide and water, which can also lead to sodium and fluid overload. Sodium bicarbonate replacement should be considered as a last resource and is not recommended in patients with hypoperfusion induced lactic acidema with $\mathrm{pH} \_>7.15$.

\section{Venous thromboembolic events prophylaxis}

Patients with severe sepsis have higher risk of venous thromboembolic events (VTEs) due to one or more risk factors, including advanced age, chronic cardiopulmonary disease, recent surgery, immobilization, in-dwelling vascular catheters, and previous VTE history [ 140 ]. Sepsis is associated with systemic activation of coagulation and frequently results in disseminated intravascular coagulation (DIC) [ 141 ]. Also hypoperfusion and reperfusion seen in patients with shock has been associated with endothelial damage. Indeed, VTE prophylaxis using unfractionated heparin (UFH), low molecular weight heparin (LMWH), and/or mechanical methods has become standard of care in most institutions [ 142 ].

\section{Stress ulcer prophylaxis}

Stress ulcers are a common complication in ICU admissions and more importantly in those related to sepsis. A clear etiology has not been established but ischemia and reperfusion are thought to cause the mucosal defenses to break down, resulting in mucosal injury and ulceration [ 143 ]. During sepsis and septic shock, reduced blood flow, hypoperfusion, and reperfusion injury may be seen secondary to hypotension or hypovolemia. These are the most common risk factors contributing to mucosal injury, hence leading to development of stress ulcers. 
Treatment options include $\mathrm{H}_{2}$ receptor antagonists $\left(\mathrm{H}_{2}\right.$ Ras) which act by decreasing gastric acid secretion through reversible, competitive inhibition of histamine-stimulated acid secretion and are effective in reducing basal acid production. However, because gastrin and acetylcholine provide alternative pathways to the stimulation of acid secretion, acid suppression with $\mathrm{H}_{2} \mathrm{RAs}$ is incomplete.

Proton pump inhibitors (PPIs) inhibit the final step in acid production, the generation of gastric hydrogen ions via hydrogen potassium adenosinetriphosphatase; they provide longlasting suppression of acid secretion.

Both $\mathrm{H}_{2}$ Ras and PPIs have been proved effective for prevention of stress ulcers and superiority of one treatment option over the other has not been clearly established in clinical trials. Careful considerations must be taken on greater incidence of ventilator associated pneumonias on patients with sepsis already placed on mechanical ventilation, due to an increase in stomach $\mathrm{pH}$. Physicians most weight individual risk over benefits, especially in those patients at greater risks of developing gastrointestinal bleeding.

\section{References}

[1] Weinstein MP, Reller LP, Murphy JR, et al: the clinical significance of positive blood cultures: A comprehensive analysis of 500 episodes of bacteremia and fungemia in adults. Laboratory and epidemiologic observations. Rev Infect Dis 1983; 5: 35-53

[2] Giamarellos-Bourboulis EJ, Giannopoulou P, Grecka P, et al: Should procalcitonin be introduced in the diagnostic criteria for the systemic inflammatory response syndrome and sepsis? J Crit Care 200419:152-157

[3] Tenover FC: Rapid detection and identification of bacterial pathogens using novel molecular technologies: Infection control and beyond. Clin Infect Dis 2007; 44:418 $-423$

[4] Jimenez MF, Marshall JC: Source control in the management of sepsis. Intensive Care Med 2001; 27:S49 -S62

[5] Moss RL, Musemeche CA, Kosloske AM: Necrotizing fascitis in children: Prompt recognition and aggressive therapy improve survival. J Pediatr Surg 1996; 31:1142-1146

[6] Bufalari A, Giustozzi G, Moggi L: Postoperative intraabdominal abscesses: Percutaneous versus surgical treatment. Acta Chir Belg 1996; 96:197-200

[7] Evans A, Winslow BH: Oxygen saturation and hemodynamic response in critically ill mechanically ventilated adults during intrahospital transport. Am J Crit Care 1995; 4:106 -111

[8] Centers for Disease Control and Prevention:Guidelines for the prevention of intravascular catheter-related infections. MMWR Morbid Mortal Wkly Rep 2002; 51(RR-10):1-29

[9] O'Grady NP, Alexander M, Dellinger EP, et al: Guidelines for the prevention of intravascular catheter-related infections. Clin Infect Dis 2002; 35:1281-1307

[10] Mier J, Leon EL, Castillo A, et al: Earlyversus late necrosectomy in severe necrotizing pancreatitis. Am J Surg 1997; 173:71-75 
[11] Kumar A, Roberts D, Wood KE, et al: Duration of hypotension prior to initiation of effective antimicrobial therapy is the critical determinant of survival in human septic shock. Crit Care Med 2006; 34:1589 -1596

[12] Morrell M, Fraser VJ, Kollef MH: Delaying the empiric treatment of candida bloodstream infection until positive blood culture results are obtained: A potential risk factor for hospital mortality. Antimicrob Agents Chemother 2005; 49:3640 -3645

[13] Nguyen MH, Peacock JE Jr, Tanner DC, Morris AJ, Nguyen ML, Snydman DR, Wagener MM, Yu VL: Therapeutic approaches in patients with candidemia. Evaluation in a multicenter, prospective, observational study. Arch Intern Med 1995;155(22):2429

[14] Nucci M, Colombo AL, et al. Risk factors for death in patients with candidemia. Infect Control Hosp Epidemiol 1998;19(11):846.

[15] Lin MY et al.Prior antimicrobial therapy and risk of hospital- acquired Candida glabrata and Candida krusei fungemia; a case - control study. Antimicrob Agents Chemother.2005;49(11):4555.

[16] Chow JK, Golan Y et al. Risk factors for albicans and non-albicans candidemia in the intensive care unit. Crit Care Med 2008;3697):1993

[17] Leibovici L, Shraga I, Drucker M, et al: The benefit of appropriate empirical antibiotic treatment in patients with bloodstream infection. J Intern Med 1998; 244:379-386

[18] Ibrahim EH, Sherman G, Ward S, et al: The influence of inadequate antimicrobial treatment of bloodstream infections on patient outcomes in the ICU setting. Chest 2000;118:146 -155

[19] herapy. Crit Care Med 2007; 25:1888 -1895Hughes WT, Armstrong D, Bodey GP, et al:2002 Guidelines for the use of antimicrobial agents in neutropenic patients with cancer.http://www.idsociety.org.

[20] Klastersky J: Management of fever in neutropenic patients with different risks of complications. Clin Infect Dis $2004 ; 39$ (Suppl 1):S32-S37

[21] Safdar N, Handelsman J, Maki DG: Does combination antimicrobial therapy reduce mortality in Gram-negative bacteraemia? A meta-analysis. Lancet Infect Dis 2004;4:519 -527

[22] Paul M, Silbiger I, Grozinsky S, et al: Beta lactam antibiotic monotherapy versus beta lactam-aminoglycoside antibiotic combination therapy for sepsis. Cochrane Database Syst Rev 2006; (1):CD003344

[23] Garnacho-Montero J, Sa-Borges M, SoleViolan J, et al: Optimal management therapy for Pseudomonas aeruginosa ventilator associated pneumonia: An observational,multicenter study comparing monotherapy with combination antibiotic . Crit Care Med 2007; 25:1888 -1895

[24] Bone RC, Balk RA, Cerra FB, et al. Definitions for sepsis and organ failure and guidelines for the use of none invasive therapies in sepsis. The ACCP/SCCM Consensus Conference committee. American Colleague of Chest Physician/Society Critical Care Medicine. Chest 1992; 1644-55.

[25] Marshall JC, Cook DJ, Christou NV, et al. Multiple organ dysfunction score: a reliable descriptor of complex clinical outcome. Crit Care Med.1995; 23:1638-52. 
[26] Astiz ME, Rackow EC, Falk JL, Kaufman BS, Weil MH. Oxygen delivery and consumption in patients with hyperdynamic septic shock. Crit care Med 1987; 15:26-8.

[27] Ferreira FL, Bota DP, Bross A, et al. Serial evaluation of the SOFA score to predict outcome in critically ill patient. JAMA 2001; 286:174-1758.

[28] Rivers E, Nguyen B, Havstad S, et al; Early Goal Directed Therapy Collaborative group. Early Goal Directed Therapy in the treatment of severe sepsis and septic shock. N Engl J Med.2001; 345; 1368-77.

[29] Dellinger RP, Levy MM, Carlet JM, et al; Surviving Sepsis Campaign Guidelines for management of severe sepsis and septic shock: Crit Care med 2004; 32 859873.

[30] Dellinger RP, Levy MM, Carlet JM, et al; International Surviving Sepsis Campaign Guidelines Committee, American Association Of Critical Care Nurses, American College Of Physician, et al. Surviving Sepsis Campaign: International guidelines of management of severe sepsis and septic shock: 2008 Crit Care med 2008;36;296-327.

[31] Magder S: Central venous pressure: A Useful but not so simple measurement. Crit Care Med 2206; 34:2222-2227.

[32] Bendjelid K: Right atrial pressure: Determinant or result of change in venous return? Chest 2005; 1283639-3640.

[33] Bendjelid K, Romand JA: Fluid responsiveness in mechanical ventilated patients: A review of indices used in intensive care. Intensive care Med 2033; 352-360.

[34] Malbrain ML, Deeren D, De Potter TJ: Intra-abdominal hypertension in the critically ill: It is time to pay attention. Curr Opin Crit care 2005; 11: 156-171.

[35] Varpula M, Tallgen M, Saukkonen $K$, et al: Hemodynamic variables related to outcome in septic shock. Intensive Care Med 2005; 31 1066-1071.

[36] Patton HD, Fuchs, AF, Hille B, Sacher AM, Steiner R (1989) Textbook of physiology, Sauders Phyladelphia.

[37] Harvey S, Harrison DA, Singer M, et al. Assessment of the clinical effectiveness or pulmonary artery catheters in management of patient in intensive care. (PACMan): a randomized controlled trial. Lancet 2005; 366: 472-477.

[38] Wheeler AP, Bernard GR, Thompson BT et al. Pulmonary artery versus central venous catheter to guide treatment of acute lung injury. N ENG J Med 2006; 354: 2213-2224.

[39] Supriya Maddirala, MD, Akram Kanm, MD. Optimizing hemodynamic support in septic shock using central and mixed venous oxygen saturation. Crit Care Clin 26 (2010) 323-333.

[40] Reinhart K, Kuhn HJ, Hartog C, Bredele DL. Continuous central venous and pulmonary artery oxygen saturation monitoring in the critically ill. Intensive Care Med 2004, 30:1572-8.

[41] Finfer S, Bellomo R, Boyce N, Et al. SAFE study investigators. A comparison of albumin and saline for fluid resuscitation in the intensive care unit. $\mathrm{N}$ Engl J med. 2004; 32, 2029-2038. 
[42] Brunkhorst FM, Engel C, Bloos F, et al. German competence network Sepsis (SepNet). Intensive insulin therapy and pentastarch resuscitation in severe sepsis. N Engl J med. 2008; 358; 125-139.

[43] Smith MD, McPhail B, Harrison Mr, et al. Value and limitations of transesophageal echocardiography in determination of left ventricular volumes and ejection fraction. Jam Coll Cardiol 1992, 19:1213-1222.

[44] Michard F, Boussat S, Chemela D, Richard C, et al. Clinical use of respiratory changes in arterial pulse pressure to monitor the hyperdynamic effects of PEEP. Am J Resp Crit care Med 1999; 15:935-939.

[45] Gunn SR, Pinsky MR. Implications of arterial pressure variations in patients in the intensive care unit. Curr Opin Crit care 2001:7:212-217.

[46] Humprey H, Hall J, Szajder I et al. Improved survival in ARDS patient associated with reduction of in pulmonary capillary wedge pressure. Chest 1190, 97:11761180 .

[47] Simmons RS, Berdine GC, Seidefeld JJ, et al. Fluid balance in the adult respiratory distress syndrome. Am Respir Dis 1987; 135:924-929.

[48] Updaya A. Tilluckdharry L, Muralidharam V, et al. Fluid balance and weaning outcomes. Intensive Care med 2005; 31:1643-1647.

[49] Wiedemann HP, Wheeler AP, Bernard GR, et al. Comparison of two fluid management strategies in acute lung injury. N Engl J Med 2006; 354:2564-2575.

[50] Boyd JH, Forbes J, Nakada TA, et al: fluid resuciatation in septic shock: a positive fluid balance and elevated central venous pressure are associated with increased mortality. Crit Care Med 2011, 39:259-265.

[51] Durairaj L, Schmidt GA. Fluid therapy in resuscitated sepsis: less is more. Chest. 2008; 133:252-263. doi: 10.1378/chest.07-1496.

[52] Hollenberg SM, Ahrens Ts, Annane D, et al. Practice parameters for hemodynamic support of sepsis in adult patients: 2004 update. Crit Care Med 2004:3219281948.

[53] Desjars P, Pinaud M, Bugnon D, et al. Norepinephrine therapy has no deleterious renal effects in human septic shock. Crit Care Med 1989; 17:426-9.

[54] Desjars P, Pinaud M, Tasseau F, et al. A reappraisal of norepinephrine therapy inhuman septic shock. Crit Care Med 1987; 15:134-7.

[55] Hesselvik JF, Brodin B. Low dose norepinephrine in patients with septic shock and oliguria: effects on afterload, urine flow, and oxygen transport. Crit Care Med $1989 ; 17: 179-80$.

[56] Meadows D, Edwards JD, Wilkins RG, et al. Reversal of intractable septic shock with norepinephrine therapy. Crit Care Med 1988; 16:663-7.

[57] Martin C, Perrin G, Saux P, et al. Effects of norepinephrine on right ventricular function in septic shock patients. Intensive Care Med 1994; 20:444-7.

[58] Martin C, Saux P, Eon B, et al. Septic shock: a goal-directed therapy using volume loading, dobutamine and/or norepinephrine. Acta Anaesthesiol Scand 1990; 34:413-7.

[59] Martin C, Eon B, Saux P, et al. Renal effects of norepinephrine used to treat septic shock patients. Crit Care Med 1990; 18:282-5. 
[60] Redl-Wenzl EM, Armbruster C, Edelmann G, et al. The effects of norepinephrine on hemodynamics and renal function in severe septic shock states. Intensive Care Med 1993; 19:151-4.

[61] Marik PE, Mohedin M. The contrasting effects of dopamine and norepinephrine on systemic and splanchnic oxygen utilization in hyperdynamic sepsis. JAMA 1994; 272:1354-7.

[62] Ruokonen E, Takala J, Kari A, et al. Regional blood flow and oxygen transport in septic shock. Crit Care Med 1993; 21:1296-303.

[63] Martin C, Papazian L, Perrin G, et al. Norepinephrine or dopamine for the treatment of hyperdynamic septic shock. Chest 1993; 103:1826-31.

[64] Levy B, Bollaert PE, Charpentier C, et al. Comparison of norepinephrine and dobutamine to epinephrine for hemodynamics, lactate metabolism, and gastric tonometric variables in septic shock: a prospective, randomized study. Intensive Care Med 1997; 23:282-7.

[65] Martin C, Viviand X, Arnaud S, et al. Effects of norepinephrine plus dobutamine or norepinephrine alone on left ventricular performance of septic shock patients. Crit Care Med 1999; 27:1708-13.

[66] Chernow B, Roth BL. Pharmacologic manipulation of the peripheral vasculature in shock: clinical and experimental approaches. Circ Shock 1986; 18:141-55.

[67] De Backer D, Briston P, Devereiendt J. et al. Comparison of dopamine and norepinephrine in the treatment of shock. N Engl J Med 2010; 362779-89.

[68] Martin C, Viviand X, Leone M, et al. Effect of norepinephrine on the outcome of septic shock. Crit Care Med 2000; 28:2758-65.

[69] De Backer D, Creteur J, Silva E, et al. Effects of dopamine, norepinephrine, and epinephrine on the splanchnic circulation in septic shock: which is best? Crit Care Med 2003; 31:1659-67.

[70] Regier B, Rapin M, Gory G, et al. Hemodynamic effects of dopamine in septic shock. Intensive Care Med. 1977,3: 47-53.

[71] Bellomo R, Chapman M, Finfer S, et al. Low dose dopamine in patents with early renal dysfunction: a placebo: A Placebo- controlled randomized trial. Australian and New Zealand Intensive Care Society (ANZICS) Clinical Trials Groups. Lancet. 2000; 356:2139-2143.

[72] Van den Berghe G, de Zegher F, Lauwers P. Dopamine suppress pituitary function in infants and children. Crit Care Med. 1994; 22:1747-1753.

[73] Oberbeck R, Schmitz D, Wilsnack K, et al. Dopamine affects cellular immune functions during polymicrobial sepsis. Intensive Care Med 2006; 32:32731-739.

[74] Sakr Y. Reinhart K, Vincent JL, et al. Does dopamine administration in shock influence outcome? Results of the Sepsis Occurrence in Acutely Ill Patients (SOAP) study. Crit Care Med 2006; 34: 589-597.

[75] Hannemann L, Reinhart K, Grenzer O. et al Comparison of dopamine to dobutamine and norepinephrine for oxygen delivery and uptake in septic shock . Crit Care Med.1995; 23:1962-1970.

[76] Meier-Hellman A, Reinhart K. Effects of catecholamines on regional perfusion and oxygenation in critically ill patients. Acta Anestesiol Scand Suppl 1995; 107:239248. 
[77] Bollart PE, Bauer P, Audibert G, et al. Effects of norepinephrine on hemodynamics and oxygen metabolism in dopamine- resistant septic shock. Chest 1990; 98:949953.

[78] Wilson W, Lipman J, Scribante J, et al. Septic Shock: Does adrenaline have role as first line inotropic agent?. Anesth Intens Care 1992;20:470-4.

[79] Levy B., Bollaert P.E., Charpentier C., et al. Comparison of norepinephrine and dobutamine to epinephrine for hemodynamics,lactate metabolism and gastric tonometric variables in septic shock:A prospective,randomized study.Intensive Care Med 1997; 23:282-287.

[80] Zhou S.X., Qiu H.B., Huang Y.Z., et al: Effects of norepinephrine, epinephrine, and norepinephrine-dobutamine on systemic and gastric mucosal oxygenation in septic shock. Acta Pharmacol Sin 2002; 23:654-658.

[81] Meier-Hellmann A., Reinhart K., Bredle D.L., et al: Epinephrine impairs splanchnic perfusion in septic shock. Crit Care Med 1997; 25:399-404.

[82] Martikainen T.J., Tenhunen J.J., Giovannini I., et al: Epinephrine induces tissue perfusion deficit in porcine endotoxin shock: Evaluation by regional $\mathrm{CO}(2)$ content gradients and lactate-to-pyruvate ratios. Am J Physiol Gastrointest Liver Physiol 2005; 288:G586-G592.

[83] De Backer D, Cretaur J Silva E, et al. Effects of dopamine, norepinephrine, and epinephrine in the splenic circulation in septic shock: which are the best: Crit Care Med 2003; 31:1659.

[84] Myburgh J.A., Higgins A., Jovanovska A., et al:A comparison of epinephrine and norepinephrine in critically ill patients. Intensive Care Med 2008; 34:22262234.

[85] Annane D., Vignon P., Renault A., et al:Norepinephrine plus dobutamine versus epinephrine alone for management of septic shock:A randomized trial .Lancet 2007; 370:676-684.

[86] Reinelt H., Radermacher P., Kiefer P., et al:Impact of exogenous beta-adrenergic receptor stimulation on hepatosplanchnic oxygen kinetics and metabolic activity in septic shock. Crit Care Med 1999; 27:325-331.

[87] Holmes C.L., Patel B.M., Russell J.A., Walley K.R.: Physiology of vasopressin relevant to management of septic shock. Chest 2001; 120:989-1002.

[88] Barrett B.J., Parfrey P.S.: Clinical practice: Preventing nephropathy induced by contrast medium. N Engl J Med 2006; 354:379-386.

[89] Kusano E, TianS, UminoT, et al. Arginine-vasopressin inhibits interleukin-1betastimulated nitric oxide and cyclic guanosine monophosphate production via the V1 receptor in cultured rat vascular smooth muscle cells. J Hypertens 1997; 15:627-32.

[90] Wakatsuki T, Nakaya Y, Inoue I. Vasopressin modulates K (1)-channel activities of cultured smooth muscle cells from porcine coronary artery. Am J Physiol 1992; 263:H491-6.

[91] Malay M.B., Ashton Jr R.C., Landry D.W, Townsend R.N.:Low dose vasopressin in the treatment of vasodilatory septic shock. J Trauma 1999; 47:699-703.discussion 705. 
[92] Buijk S.E., Bruining H.A.: Vasopressin deficiency contributes to the vasodilation of septic shock. Circulation 1998; 98:187.

[93] Goldsmith S. R.: Vasopressin deficiency and vasodilation of septic shock. Circulation 1998; 97:292-293.

[94] Reid I. A.: Role of vasopressin deficiency in the vasodilation of septic shock. Circulation 1997; 95:1108-1110.

[95] Patel B. M., Chittock D.R., Russell J.A., Walley K. R.: Beneficial effects of short term vasopressin infusion during severe septic shock. Anesthesiology 2002; 96: 576-582.

[96] Dunser MW, Mayr AJ, Ulmer $\mathrm{H}$, et al. Arginine vasopressin in advanced vasodilatory shock: a prospective, randomized, controlled study. Circulation 2003; 107:2313-9.

[97] Russell JA, Walley KR, Singer J, et al. Vasopressin versus norepinephrine infusion in patients with septic shock. N Engl J Med 2008; 358:877-87.

[98] Russell J.A., Walley K.R., Gordon A.C., et al: Interaction of vasopressin infusion, corticosteroid treatment and mortality of septic shock. Crit Care Med 2009; 37:811-818.

[99] Meier-Hellmann A, Bredle DL, Specht M, et al. The effects of low-dose dopamine on splanchnic blood flow and oxygen utilization in patients with septic shock. Intensive Care Med 1997; 23:31-7.

[100] Marshall JC. Inflammation, coagulopathy, and the pathogenesis of multiple organ dysfunction syndrome Crit Care Med 2001;29:S99-106.

[101] Soni A, Pepper GM, Wyrwinski PM, Ramirez NE, Simon R, Pina T, et al. Adrenal insufficiency occurring during septic shock: Incidence, outcome, and relationship to peripheral cytokine levels. Am J Med 1995;98:266-71.

[102] Szabo C, Thiemermann C, Wu CC, Perretti M, Vane JR. Attenuation of the induction of nitric oxide synthetase by endogenous glucocorticoids accounts for endotoxin tolerance in vivo. Proc Nati Acad Sci U S A 1994;91:271-5.

[103] Schumer W: Steroids in the treatment of clinical septic shock. Ann Surg 1976; 184:333-341

[104] Annane D. Corticosteroids for septic shock. Crit Care Med 2001;29:S117-20

[105] Russell JA, Walley KR, Gordon AC, et al: Interaction of vasopressin infusion, corticosteroid treatment, and mortality of septic shock. CritCare Med 2009; 37:811- 818

[106] Sprung, CL MD., Annane D MD., et al: Hydrocortisone Therapy for Patients with Septic Shock. N Engl J Med 2008;358:111-24.

[107] Esmon CT. The protein C anticoagulant pathway. Arterioscler Thromb 1992;12:13545.

[108] Bernard GR, Vincent JL, Laterre PF, et al.Efficacy and safety of recombinant human activated protein $\mathrm{C}$ for severe sepsis. New England Journal Medicine 2001;344(10):699-709.

[109] Laterre PF, Abraham E, Janes JM, Trzaskoma BL, Correl NL, Booth F. ADDRESS (ADministration of DRotrecogin alfa[activated] in Early stage Severe sepsis) long-term follow-up: one year safety and efficacy evaluation. Critical Care Medicine 2007;35(6):1457-63. 
[110] Laterre PF Abraham, Garg R, Levy H, Talwar D, Trzaskoma BL, et al.Drotrecogin alfa (activated) for adults with severe sepsis and a low risk of death. New England Journal of Medicine 2005;353 (13):1332-41.

[111] Tan JS. Infectious complications in patients with diabetes mellitus. Int Diabetes Monitor. 2000;12:1-7.

[112] Inzucchi SE. Management of hyperglycemia in the hospital setting. N Engl J Med 2006; 355:1903-11.

[113] Van den Berghe G, Wouters P, Weekers F, et al. Intensive insulin therapy in critically ill patients. N Engl J Med 2001; 345:1359-67.

[114] Van den Berghe G, Wilmer A, Hermans G, et al. Intensive insulin therapy in the medical ICU. N Engl J Med 2006; 354:449-61.

[115] The NICE-SUGAR Study investigators. Intensive versus Conventional Glucose Control in Critically Ill Patients N Engl J Med 2009; 360:13.

[116] Bernard GR, Artigas A, Brigham KL, Carlet J, Falke K, Hudson L, et al. The American- European Consensus Conferences on ARDS. Definitions, mechanisms, relevant outcomes, and clinical trial coordination. Am J Respir Crit Care Med 1994;149:818-24

[117] Ventilation with lower tidal volumes as compared with traditional tidal volumes for acute lung injury and acute respiratory distress syndrome. Acute Respiratory Distress Syndrome Network. N Engl J Med 2000;342 (18):1301-8

[118] Dellinger RP,Levy MM,Carlet JM,Bion J,Parker MM,Jaeschke R et al. Surviving Sepsis Campaign: International guidelines for management of severe sepsis and septic shock: 2008. Crit Care Med. 2008; 36(1):296-327.

[119] Malhotra A. Low-tidal-volume ventilation in the acute respiratory distress syndrome. N Engl J Med 2007;357(11):1113-20

[120] Brower RG,Lanken PN,MacIntyre N,Mathay MA,Morris A,Ancukiewicz M,et al.National Heart,Lung and Blood Institute ARDS Clinical Trials Network.Higher versus lower positive end-expiratory pressures in patients with the acute respiratory distress syndrome.N Engl J Med 2004;351(4):327-36

[121] Esan A,Hess DR,Raoof S,George L,Sessler CN. Severe hypoxemic respiratory failure: part 1-ventilatory strategies Chest 2010;137(5);1203-1216

[122] Esan A,Hess DR,Raoof S,George L,Sessler CN,Feihl F,Perret C.Permissive hypercapnia. How permissive should we be? Am J Resp Crit Care Med 1994;150:1722-37

[123] Raoof S,Goulet K,Esan A,Hess DR,Sessler CN. Severe hypoxemic respiratory failure: part 2-nonventilatory strategies. Chest 2010;137(6);1437-1448

[124] Agarwal R. Non invasive ventilation in Acute Lung Injury/ Acute respiratory Distress Syndrome. In: Esquinas AM. Noninvasive Mechanical Ventilation: Theory, Equipment and Clinical applications. Springer-Verlag Berlin Heidelberg 2010: 241-248

[125] Dellinger P,Levy MM,Carlet JM,Bion J,Parker MM,Jaeschke R et al. Surviving Sepsis Campaign: International guidelines for management of severe sepsis and septic shock: 2008. Crit Care Med. 2008; 36 (1):296-327. 
[126] Jacob J, Fraser GL, Coursin DB, Riker RR, Fontaine D, Wittbrodt ET, et al. Clinical practice guidelines for the sustained use of sedatives and analgesics in the critically ill adult. Crit Care Med. 2002;30 (1):119-41.

[127] Brook AD, Ahrens TS, Schaiff R,Prentice D,Sherman G,Shannon W et al: Effect of a nursing-implemented sedation protocol on the duration of mechanical ventilation. Crit Care Med 1999; 27(12):2609-15

[128] Girard TD, Kress JP, Fuchs BD, Thomason JW, Schweickert WD, Pun BT, et al. Efficacy and safety of a paired sedation and ventilator weaning protocol for mechanically ventilated patients in intensive care (Awakening and Breathing Controlled trial): a randomised controlled trial. Lancet. 2008;371 (9607):126-34.

[129] Payen JF, Bru O, Bosson JL, Lagrasta A, Novel E, Deschaux I, et al. Assessing pain in critically ill sedated patients by using a behavioral pain scale. Crit Care Med. 2001;29 (12):2258-63.

[130] Murray MJ, Cowen J, DeBlock H, Erstad B, Gray AW Jr, Tescher AN, et al. Clinical practice guidelines for sustained neuromuscular blockade in the adult critically ill patient. Crit Care Med. 2002;30 (1):142-56.

[131] Papazian L.Foerl Jm,Gacouin A,Penot-Rangon C,Perrin G,Loundou A,et al. Neuromuscular blockers in early acute respiratory distress syndrome. N Engl J Med. 2010;363 (12):1107-16.

[132] Morandi A, Brummel NE, Ely EW. Sedation, delirium and mechanical ventilation: the 'ABCDE' approach. Curr Opin Crit Care. 2011;17(1):43-9

[133] Uchino S, Kellum JA, Bellomo R, Doig GS, Morimatsu H, Morgera S, Schetz M, Tan I, Bouman C, Macedo E, Gibney N, Tolwani A,Ronco C: Acute renal failure in critically ill patients: A multinational, multicenter study. JAMA 2005;294:813-818

[134] Robert W. Schrier, M.D., and Wei Wang, M.D. Acute Renal Failure and Sepsis. N Engl J Med 2004; 351:159-169

[135] Liaño F, Junco E, Pascual J, Madero R, Verde E. The spectrum of acute renal failure in the intensive care unit compared with that seen in other settings. The Madrid Acute Renal Failure Study Group. Kidney Int 1998; 53:S16-24

[136] Bellomo R, Ronco C, Kellum JA, Mehta RL, Palevsky P, Acute Dialysis Quality Initiative workgroup.Acute renal failure - definition, outcome measures, animal models, fluid therapy and information technology needs: the Second International Consensus Conference of the Acute Dialysis Quality Initiative (ADQI). Group Crit Care. 2004;8(4):R204.

[137] Mehta RL, Kellum JA, Shah SV, Molitoris BA, Ronco C, Warnock DG, Levin A, Acute Kidney Injury Network.. Acute Kidney Injury Network: report of an initiative to improve outcomes in acute kidney injury. Crit Care. 2007;11(2):R31.

[138] Emili, S., N. A. Black, R. V. Paul, C. J. Rexing, and M. E. Ullian. 1999. A protocolbased treatment for intradialytic hypotension in hospitalized hemodialysis patients. Am. J. Kidney Dis. 33:1107-1114.

[139] Cooper DJ, Walley KR, Wiggs BR, et al: Bicarbonate does not improve hemodynamics in critically ill patients who have lactic acidosis: A prospective, controlled clinical study. Ann Intern Med 1990; 112:492-498 
[140] Cook DJ, Crowther MA, Meade MO, Douketis J, for the VTE in the ICU Workshop Participants. Prevalence, incidence, and risk factors for venous thromboembolism in medical-surgical intensive care unit patients. J Crit Care 2005;20:309-313

[141] Sacha Zeerleder, MD, C. Erik Hack, MD, PhD, Walter A. Wuillemin, MD; PhD. Disseminated Intravascular Coagulation in Sepsis. CHEST October 2005 vol. 128 no. 4 2864-2875

[142] Perez J, Dellinger RP, and International Sepsis Forum. Other supportive therapies in sepsis. Intensive Care Med 2001;27(Suppl 1):S116-S127

[143] Spirt MJ. Stress-related mucosal disease. Curr Treat Options Gastroenterol. 2003;6: 135-145. 


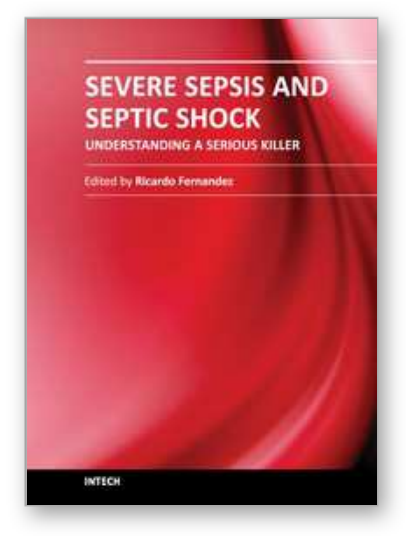

\author{
Severe Sepsis and Septic Shock - Understanding a Serious Killer \\ Edited by Dr Ricardo Fernandez
}

ISBN 978-953-307-950-9

Hard cover, 436 pages

Publisher InTech

Published online 10, February, 2012

Published in print edition February, 2012

Despite recent advances in the management of severe sepsis and septic shock, this condition continues to be the leading cause of death worldwide. Some experts usually consider sepsis as one of the most challenging syndromes because of its multiple presentations and the variety of its complications. Various investigators from all over the world got their chance in this book to provide important information regarding this deadly disease. We hope that the efforts of these investigators will result in a useful way to continue with intense work and interest for the care of our patients.

\title{
How to reference
}

In order to correctly reference this scholarly work, feel free to copy and paste the following:

D. Boodoosingh, C. Cruz, M. Egozcue, R. Fernandez, V. Salinas and S. Valentin (2012). Update in the Treatment of Severe Sepsis and Septic Shock, Severe Sepsis and Septic Shock - Understanding a Serious Killer, Dr Ricardo Fernandez (Ed.), ISBN: 978-953-307-950-9, InTech, Available from:

http://www.intechopen.com/books/severe-sepsis-and-septic-shock-understanding-a-serious-killer/update-inthe-treatment-of-severe-sepsis-and-septic-shock

\section{INTECH}

open science | open minds

\section{InTech Europe}

University Campus STeP Ri Slavka Krautzeka 83/A 51000 Rijeka, Croatia Phone: +385 (51) 770447 Fax: +385 (51) 686166 www.intechopen.com

\section{InTech China}

Unit 405, Office Block, Hotel Equatorial Shanghai No.65, Yan An Road (West), Shanghai, 200040, China 中国上海市延安西路65号上海国际贵都大饭店办公楼 405 单元 Phone: +86-21-62489820

Fax: +86-21-62489821 
(C) 2012 The Author(s). Licensee IntechOpen. This is an open access article distributed under the terms of the Creative Commons Attribution 3.0 License, which permits unrestricted use, distribution, and reproduction in any medium, provided the original work is properly cited. 